\title{
DROGAS: PARADOXOS NO CAMPO DO TRABALHO
}

\author{
DRUGS: PARADOXES IN THE FIELD OF WORK \\ DROGAS: PARADOJAS EN EL CAMPO DE TRABAJO
}

Daniela Tonizza de Almeida*

Thaisa Vilela Fonseca Amaral ${ }^{*}$

\begin{abstract}
RESUMO
Tomando como ponto de partida o debate conceitual sobre o termo drogas e seu uso na contemporaneidade, pretende-se compreender, no trabalho em tela, como os efeitos deletérios das políticas neoliberais no mundo do trabalho incidem sobre os sujeitos envolvidos no tráfico de drogas, no varejo e no consumo abusivo de psicoativos considerados ilícitos. Para tanto, problematizam-se as práticas discursivas em torno das drogas e seus efeitos na produção de uma corporalidade específica, de um tipo social que será alvo de rejeição. Considera-se que a droga, enquanto mercadoria e enquanto dispositivo de controle social, institui um campo de disputa política, em que a vida, apreendida como precária, não é reconhecida. Essa estratégia atende aos interesses econômicos de determinados grupos sociais que lucram com o encarceramento da população marginalizada e com a medicalização da vida. Tais discussões apontam para a urgente superação da falaciosa guerra às drogas.
\end{abstract}

Palavras-chave: Drogas. Trabalho. Abjeto.

\section{ABSTRACT}

Taking as the starting point the conceptual debate on the term 'drugs' and its use in contemporary times, the paper seeks to understand how the deleterious effects of neoliberal policies in the world of labor affect subjects involved in retail drug trafficking and in the abusive consumption of psychoactive drugs considered to be ilicit. In this sense, it discusses the discursive practices around drugs and its effects on the production of a specific corporeality, of a social type that will be targetted to rejection. It is considered that the drug, as a commodity and as a social control device, establishes a political dispute field where life, perceived as precarious, is not recognized. Such strategy serves the economic interests of certain social groups that profit from the incarceration of marginalized populations and the medicalization of life. These debates point out to the urgent overcoming of fallacious war on drugs.

Keywords: Drugs. Labor. Abject.

* Doutoranda em Psicologia Social pela Universidade Federal de Minas Gerais. E-mail: danielatonizza@gmail.com

** Doutoranda em Psicologia Social pela Universidade Federal de Minas Gerais. E-mail: thaisavfa@gmail.com 


\section{RESUMEN}

Tomando como punto de partida el debate conceptual sobre el término 'droga' y su uso en la época contemporánea, el artículo pretende entender cómo los efectos nocivos de las políticas neoliberales en el mundo del trabajo afectan a los sujetos implicados en el tráfico de drogas minorista y en el consumo de drogas psicoactivas consideradas ilegales. En ese sentido,serán problematizadas las prácticas discursivas en torno de las drogas y sus efectos en la producción de una corporalidad específica, de un tipo social que será sujeto de rechazo. Se considera que la droga, como una mercancía y como un dispositivo de control social, establece un campo de disputa política, donde la vida, percibida como débil, no se reconoce. Esta estratégia sirve a los intereses económicos de determinados grupos sociales que se benefician con la encarcelación de las poblaciones marginadas y la medicalización de la vida. Dichas discusiones apuntan a la superación urgente de la guerra falaz contra las drogas.

\section{INTRODUÇÃO}

5 inegável que as drogas, aquelas consideradas ilícitas, têm ocupado o centro do debate sobre certo mal-estar contemporâneo. A associação do termo drogas com dependência ou mesmo com a sensação de medo e insegurança está estampada nos conteúdos da mídia e continuada no trato, sobretudo, das campanhas "antidrogas".

A droga, enquanto objeto de consumo, aparece como um mal em si mesmo, suscitando ações e interpretações genéricas, descoladas de uma reflexão aprofundada e crítica do tema (Tiburi \& Dias, 2013). Nesse viés, motes como "Diga não às drogas" ou "Crack, é possível vencer" são signos da produção desse mal-estar que oculta interesses políticos/econômicos e são também expressão de políticas de controle, que visam, sobretudo, ao controle social das vidas.

Torna-se necessário insistir na apresentação das diversas dimensões que o "problema da droga" assumiu na contemporaneidade. O enfoque moralista pauta seu discurso em uma interpretação única: as drogas ilícitas são evocadas como símbolo do mal, mal este que precisa ser combatido. Reverbera ainda, entre nós, a convocação feita pelo então presidente dos Estados Unidos da América, Richard Nixon, em 1971, de uma verdadeira ofensiva, que ganhou, na contemporaneidade, o estatuto de guerra contra as drogas.

Desconsidera-se, nessa perspectiva, que as drogas fazem parte do ethos social, com força e permanência inquestionáveis. Observa-se, em toda a história da humanidade, o consumo de drogas, de forma contínua, para os mais diversos fins: terapêuticos, religiosos, alimentícios, em ritos de sociabilidade e mesmo 
por prazer. Sabe-se, ainda, desde os escritos freudianos, que a droga, juntamente com a arte e a ciência, compóe a tríade de recursos paliativos para lidar com o mal-estar que surge como efeito colateral da vida civilizada. Apesar de todo o conhecimento sobre o consumo milenar dessas substâncias, só recentemente se dá a instauração de um discurso que pretende antagonizar droga e vida.

São diversos os modos de problematização possíveis para compreendermosa função do consumo de drogas, ao longo da história. Tomando como ponto de partida o debate conceitual sobre o termo drogas e seu uso na contemporaneidade, pretende-se, neste artigo, compreender como os efeitos deletérios das políticas neoliberais, no mundo do trabalho, incidem sobre as pessoas envolvidas no circuito da droga. Nesse percurso, colocam-se as seguintes questôes: Quais são os discursos e práticas que denotam a existência e o sentido das drogas? O que representam, no imaginário social, os sujeitos envolvidos no comércio em varejo ou no consumo abusivo das drogas consideradas ilícitas, especialmente o crack? Como a droga pode funcionar como um dispositivo utilizado para controle das populações que estão à margem do mundo do trabalho?

\section{A PRODUÇÃO DO PROBLEMA DROGA}

A narrativa hegemônica que compõe a historiografia das drogas, como bem demonstra o importante trabalho de Escohotado (1998), se assenta em marco analítico com viés moralizante e endemonizador dessas substâncias.

O que se denomina como drogas? Qual é a essência do que se entende como drogas? Pensar em situar o significado social da droga convoca a uma necessária contextualização política e histórica do tema. Via de regra, qualquer revisão historiográfica das drogas se entrelaça à matriz proibicionista estadunidense. Como bem demonstram Tiburi e Dias (2013), o viés proibicionista conduziu, ao longo da história, à compreensão do tema sempre vinculada à noção de risco, de perigo. Há aqui uma fratura ou mesmo uma inversão importante. Ao contrário do que se dissemina no senso comum, impulsionado pelo prestígio do discurso da ciência, o problema das drogas não se configura prioritariamente em razão de suas características materiais, baseadas em certa noção de risco/ toxicidade/periculosidade, ou seja, em uma nocividade inerente às substâncias psicoativas consideradas ilícitas (Tiburi \& Dias, 2013). As razóes que culminam na produção de um problema da droga estão antes atreladas "aos interesses políticos e econômicos e às demandas de dispositivos de controle da população e da legitimação de práticas de assujeitamento, racismo e criminalização" (Vianna, 2009, p. 8), como se verá adiante. Portanto, para além das propriedades que compõem o objeto droga, há um aparato discursivo construído em cima de relações de poder e saber (Vianna, 2009). 
Para Vargas (2006), os diversos campos disciplinares que se debruçam sobre a problematização do uso de drogas ilícitas associam-na à noção de falta/ fraqueza, traçando argumentações em torno de certa predisposição genética (neurobiológica), compreendendo o consumo como manifestação de atitudes regressivas, escapistas e infantilizantes (discurso dapsicologia/psicanálise), ou mesmo em razão de aspectos socioculturais (discurso das ciências sociais). Nesse sentido, os saberes sobre a droga são operados visando à "constituição do tabu e do moralismo social", ao mesmo tempo em que "se valem da ciência, usando-a em seu próprio benefício” (Tiburi \& Dias, 2013, p. 84).

O saber sobre a droga é, portanto, inerente ao contexto discursivo que o enuncia (Santiago, 2001). Como apontam Tiburi e Dias (2013, p.230), "na operação de enunciação, o discurso científico engendra objetos e produz saberes". Compreendida a partir de uma conjuntura histórica definida, a droga, enquanto objeto, assume ao mesmo tempo duas formas: a de mercadoria e a de dispositivo de controle social.

\section{A DROGA COMO MERCADORIA}

Enquanto mercadoria, no sentido marxista do termo, a droga constitui-se em um produto do trabalho, imbuído de valor de uso e valor de troca.

De acordo com Vargas (2001), os aspectos que cobrem o campo moral e que culminam na demonização contemporânea das drogas parecem ser "a contrapartida lógica e o complemento ontológico da reificação das relações humanas vigentes em sua produção e distribuição, resultante da constituição das 'drogas' enquanto mercadorias" (p.51). O conceito de reificação (Lukács, 1923) deve ser entendido aqui atrelado à ideia do fetichismo da mercadoria, tal qual formulado por Marx no livro $O$ Capital:

A mercadoria é misteriosa simplesmente por encobrir as características sociais do próprio trabalho dos homens, apresentando-as comocaracterísticas materiais e propriedades sociais inerentes aos produtos de trabalho; por ocultar, portanto, a relação social entre os trabalhos individuais dos produtores e o trabalho total, ao refleti-la como relação social existente, à margem deles, entre os produtos do seu próprio trabalho. Através dessa dissimulação, os produtos de trabalho se tornam mercadorias [...]. Mas a forma mercadoria e a relação de valor entre os produtos do trabalho, a qual caracteriza essa forma, nada têm a ver com a natureza física desses produtos nem com as relações materiais dela decorrentes. Uma relação social definida, estabelecida entre os homens, assume a forma fantasmagórica de uma relação entre as coisas [...]. Chamo isso de fetichismo, que está sempre grudado aos produtos de trabalho, quando são gerados como mercadorias. (Marx, 2013, p.94). 
Sendo assim, é possível dizer que a nocividade imputada ao objeto droga aparece ancorada nessa dissimulação, nessa exterioridade em que se dá a apresentação de um produto enquanto mercadoria, diante das relaçôes sociais entre trabalho dos produtores e trabalho total. Um fetichismo que irá assumir a forma fantasmagórica, na mercadoria droga, do diabólico, do perigoso, do patológico, do mal (Amaral, 2014).

É, portanto, no campo discursivo, engendrado nesse fetichismo, que o artefato drogas é ratificado enquanto uma problemática socialmente produzida.A partilha moral entre o bem e o mal se desdobra na separação entre drogas lícitas e ilícitas.

É nesse jogo de forças políticas que se modela a construção falaciosa em que drogas e riscos estão intimamente associados. A tão proclamada noção do risco tem validado práticas segregativas e mortíferas. Nesse sentido, o aspecto mais relevante do proibicionismo não é apenas seu fracasso, mas a violência decorrente de uma política fundada numa concepção de guerra (Karam, 2012). Não se trata verdadeiramente de uma guerra às drogas, que almeja evitar o suposto risco decorrente do consumo, mas sim de uma guerra às pessoas, sobretudo as que vivem à margem do mundo do trabalho, e que tem por finalidade o controle social, via apreensão e/ou via extermínio.

Por derradeiro, a promoção moralista da droga se desdobra para se concentrar no sujeito. As práticas associadas ao consumo ou ao comércio, consideradas malignas, contaminam os sujeitos que serão apreendidos como "diabólicos", impregnados pelo "mau caráter". Essa produção discursiva serve à criação de dispositivos de controle que têm por finalidade o descarte de tais sujeitos do corpo social.

\section{DROGAS: DISPOSITIVO DEASSUJEITAMENTO E PRODUÇÃO DE ABJETOS}

Para o governo dos homens, no mundo moderno, a proteção da vida tornouse uma estratégia política, sem a qual o desenvolvimento do capitalismo não teria sido possível. Por governo, Foucault (como citado em Duarte, 2013, p.55) compreende "o conjunto de procedimentos, técnicas e métodos que garantem a condução dos homens". Como uma das tecnologias de governo, o biopoder se encarrega da gestão da vida, atuando por meio de dispositivos encarregados de lidar com fenômenos variáveis da população, no intuito de controlar os perigos que ameaçam a vida da espécie. Nessa perspectiva foucaultiana, Tiburi e Dias (2013) redefinem os dispositivos como aquilo que captura os seres viventes, seu corpo e sua subjetividade, seja através de instituições, seus discursos e práticas, prisōes, escolas, fábricas, hospitais, seja por meio de mercadorias que engendram 
em si as relações de saber e poder de uma dada cultura e que delimitam suas fronteiras normativas.

Para Butler (2006), a normatividade refere-se aos propósitos e aspirações que direcionam a ação e a comunicação, dominam a vida incorporada e proporcionam critérios coercitivos que definem um indivíduo como normal. Regem, portanto, a vida inteligívele atam os sujeitos, através da delimitação do que é aceitável ou não. Entretanto, se não se pode prescindir das normas, no processo de socialidade, também não se pode assumir passivamente sua forma como é dada ou está fixada de antemão, já que é do movimento de subversão, em seu interior, que depende o processo de subjetivação. A norma tem, portanto, a dupla função de atar e desatar os laços sociais. Ao determinar o que deve ser incluído, automaticamente, ela também exclui (Butler, 2006).

O abjeto ${ }^{1}$ é o que, no processo de constituição do sujeito, é expulso e não categorizável, o que está fora das categorias de pensamento inteligíveis. Referese às zonas invisíveis e inabitáveis da vida social, povoadas por aqueles que não gozam de poder na hierarquia social, mas cuja condição de vida é necessária para circunscrever a esfera do sujeito, sua pretensão à autonomia e à prosperidade. A abjeção refere-se, portanto, à ação de jogar fora, descartar, excluir. Através dela se produz a diferença (Butler, 2002a).

No processo de socialidade, o abjeto "relaciona-se a todo tipo de corpos cujas vidas não são consideradas 'vidas' e cuja materialidade é entendida como não importante.” (Butler, 2002a, p.161). Nesse sentido, corpos abjetos são corpos que não são inteligíveise não têm uma existência legítima, existem apenas como um poder excluído, disruptível. "A figura viva fora das normas de vida não somente se torna um problema com o qual a normatividade tem que lidar, mas parece ser aquilo que a normatividade está fadada a reproduzir: está vivo, mas não é uma vida”. (Butler, 2015, p.22). Tais vidas, quando perdidas, não são lamentadas e nem passíveis de luto, podem ser contadas, mas não especificadas. Trata-se de indivíduos cujos corpos foram expelidos do social, descartados como excremento, como estranhos, mas que, ao mesmo tempo, produzem novas formas de gestão da própria vida, em diferentes maneiras de se colocarem em relação, além deocuparem e produziremespaços.

\footnotetext{
1 A noção de abjeto em Butler (2006) assume um caráter propositalmente contraditório, na medida em que o que se reconhece e o que se exclui nos domínios ontológico e epistemológico é efeito do poder. Para a autora, é fundamental sustentar a noção de abjeto fora de um "território conceitualmente puro". "Gostaria de protelar qualquer solução fácil até encontrar um aparato conceitual que proporcionasse à operação da abjeção uma espécie de autonomia relativa, de até mesmo um vazio, uma falta de conteúdoexatamente para não poder ser captada através de seus exemplos, de modo que seus exemplos não pudessem se tornar normativos do que queremos significar por abjeto. O que seguidamente acontece é que as pessoas apresentam teorias abstratas sobre coisas do tipo da abjeção, depois dão os exemplos, e então os exemplos se tornam normativos de todo o resto. O processo se torna paradigmático e acaba por produzir suas próprias exclusōes. Torna-se fixo e normativo, no sentido de rigidez" (Butler, 2002a, p. 161).
} 
Nesse sentido, é possível supor que os sujeitos envolvidos com a produção, a comercialização em varejo e o uso abusivo de drogas ilícitas podem ocupar, contingencialmente, no imaginário social, uma configuração de abjeto.

Especialmente,em se tratando douso abusivo de crack, por exemplo, alguns sujeitos têm sido considerados pelos trabalhadores dos serviços de saúde mental como "os mais difíceis" (Almeida, 2012), mais graves e que "beiram mesmo o insuportável" (Silva, 2010). Trata-se de usuários que perambulam entre as diversas instituições, encaminhados de um lugar para outro, seja pelos familiares, pela comunidade, pela polícia, pela justiça ou até pelos próprios profissionais da saúde, por não apresentarem demanda para o tratamento e subverterem as normas do serviço (Melo, 2010), em alguns casos com ameaças, intimidações e condutas violentas. Trata-se de sujeitos cujo diagnóstico nosológico nem sempre é claro e a intervenção medicamentosa é pouco eficaz (Alkmim, 2008). Frequentemente vivem em territórios marcados pela precariedade material, com apoio social frágil, e não raro se inserem em atividades ilícitas direta ou indiretamente relacionadas ao tráfico de drogas, colocando-se em risco de morte, adoecimento ou prisão.

Da mesma forma, trabalhadores do tráfico de drogas em varejo são considerados no corpo social como "inimigo público número um", signos da periculosidade, sujeitos capazes de produzir os piores horrores. Trata-se aqui de sujeitos que serão identificados por um traço individual: por meio de um enfoque "psicológico-moral", por vezes são incluídos em um quadro diagnóstico associado à psicopatia/perversão, por vezes são vistos possuindo uma inscrição determinante de uma falha moral. A promoção moralista/patológica da droga, enquanto construção discursiva generalizante, se desdobra, portanto, para se concentrar no sujeito, produzindo corporalidades marcadas pela transgressão, corporalidades inaceitáveis, na medida em que desorganizam a estrutura social, corporalidades que devem ser alvo de marginalização e/ou eliminação, via aprisionamento ou morte.

Esses sujeitos, sejam usuários, sejam trabalhadores do tráfico de drogas, despertam sentimentos de medo, repulsa e ódio, ao mesmo tempo em que se constituem em objeto de interesse científico, religioso, jurídico e moral. Situam-se, sobretudo, como objeto de disputa política entre diferentes grupos que pretendem normatizá-los para o convívio social, sem que se reconheça sua experiência ou se legitime qualquer expressão discursiva própria. São objetos também de disputa ética, no sentido de se definir o que é ou não uma vida digna de ser vivida. 
Os usuários abusivos de drogas e os trabalhadores do tráfico ofendem o senso esteticamente agradável e moralmente tranquilizador da normatividade burguesa. Ameaçam a limpeza ambiental e a integridade moral da sociedade, em seu esforço de garantir a saúde do corpo biológico. Ocupam as "Cracolândias" ou "Bocas": lugares produzidos pelos que não encontram lugar nos territórios delimitados pela lei e pela inclusão econômica (Silva, 2011).

É nesse sentido de desprezível, repulsivo, ameaçador que esses sujeitos podem ser considerados abjetos, entretanto, nem sempre estão fora das categorias de pensamento inteligíveis. $\mathrm{O}$ usuário de drogas tem sido apreendido, no senso comum, como o viciado, o drogado, o craqueiro, o noiado, o zumbi. Da mesma forma, aquele que trabalha na produção e comercialização das drogas ilícitas é o traficante, o vagabundo, o bandido, o demônio. Tal como são imaginados, esses sujeitos evocam os limites simbólicos, corporais e morais. Aquilo que os caracteriza/tipifica/categoriza justifica intervençōes para seu controle ou eliminação do espaço de vida compartilhado. Essas tentativas de categorização invisibilizam outros aspectos de sua condição de existência relacionados a gênero, classe social e etnia, por exemplo, e dificultam seu reconhecimento como semelhantes. Apesar de se apresentarem como elementos do campo normativo, mostram-se depurados das identificações que poderiam fazê-los parte desse campo. Devido a contingências individuais e sociais, desenvolvem uma relação com a droga, a qual produz uma corporalidade cujas categorizaçōes não se mostram suficientes, porque sempre escapa algo que não se deixa compreender e classificar.

Corpos abjetos não deveriam existir numa matriz cultural, portanto, nomear um grupo "excluído" significa, de alguma forma, reconhecê-lo. No entanto, como eles não têm a oportunidade de representar a si mesmos, correm o risco de serem tratados como menos que humanos ou de fato nem serem vistos (Butler, 2011).

Enquanto aquele que vende a droga no varejo encarna o inimigo, o mal social a ser contido e extirpado, porque o faz por "livre vontade", aquele que a usa de forma compulsiva adquire um status um pouco diferente: o sujeito "dependente químico" é aquele destituído de vontade pela ação da droga que age sobre seu corpo, contamina sua moral, sua aptidão para o trabalho e é, portanto, uma vítima do tráfico, um problema de saúde pública. Essa racionalidade deturpada oculta a condição precária de vida a que está submetida essa população. Para Butler (2015), trata-se de uma condição politicamente induzida, na qual as redes sociais e econômicas são insuficientes para o seu reconhecimento, expondo essa população a violaçôes, violência e morte. Essa população busca no Estado a proteção de que necessita, mas, paradoxalmente, o Estado é exatamente a instância da qual ela precisa ser protegida. 
De forma semelhante, para Agambem (2010), tais sujeitos tornam-se uma "vida nua", desqualificada, sem razão e, portanto, abandonada ao perecimento, por ser considerada desnecessária e ameaçadora ao modo de vida que se pretende positivar. Considerados ameaças iminentes para a sociedade, os indivíduos abandonados passam a ser capturados a partir do exterior dos limites legais, de modo que seus direitos constitucionais ficam suspensos. Ficam à mercê de quem os abandona. Transformados em ameaça iminente, esses sujeitos justificam a criação de dispositivos de segurança que são acionados em nome da vida a ser protegida, de modo que, para fazer viver uns, deixa-se morrer outros (Foucault,1999). Trata-se de um estado de exceção, no qual o poder estatal atua de maneira homicida, em nome da multiplicação da vida daqueles que se pretende fazer viver. Isso se efetiva por meio do genocídio justificado como "confrontos com a polícia", do encarceramento em massa em prisões em condiçôes indignas e das políticas sociais, de educação e de atenção à saúde bem elaboradas, porém executadas de forma precária, com subfinanciamento.

\section{DROGAS E TRABALHO}

A argumentação tecida até aqui nos leva à necessária consideração das práticas discursivas em torno das drogas ilícitas e seus efeitos na produção de uma corporalidade específica que será alvo de rejeição. Nesse sentido, é impossível desconsiderar o efeito de objetificação dos corpos que a partilha moral das drogas entre o bem e o mal, ratificada pelo discurso científico e pelo discurso jurídico entre o lícito e o ilícito irá produzir. Ora, a droga, entendida enquanto um dispositivo, captura corpos e subjetividades. O entrelaçamento entre corpo e substância culmina na produção de sujeitos marginalizados, cuja inscrição no espaço público só pode ser feita pelo bordeamento periférico.

Diante de todo o exposto, poderíamos nos questionar: mas, afinal, como o Estado lida com suas margens? Se, por um lado, a consideração do dispositivo drogas se manifesta em políticas que sustentam e legitimam uma verdadeira operação de guerra para eliminar os que vivem à margem, por outro, verifica-se que o utilitarismo econômico neoliberal não irá se furtar a transformar corpos abjetos em objetos de mercado. Nesse sentido, corpos que são de antemão considerados improdutivos, ruins para o bom desenvolvimento do trabalho e, portanto, avessos à manutenção dos princípios ordenadores do capitalismo, são objetificados e capturados pela lógica do sistema produtivista, circunscritos à dinâmica do capital.

Conforme bem aponta Wacquant (2008), o tratamento da marginalidade urbana na sociedade contemporânea está pautado pela construção de um 
estado penal, por meio de um redesenho das políticas de segurança pública. Sendo assim, fica claro como a suposta periculosidade da mercadoria droga, ao ser transformada em um problema de segurança pública, acaba por encobrir a relação perversa que irá vincular corpos abjetos com a ideologia do sistema produtivo.

Como se sabe, os efeitos deletérios das políticas neoliberais, no mundo do trabalho, produziram uma camada populacional marginalizada. Segundo Wacquant (2008, p.9), "para implantar a revolução neoliberal, Estados abandonam a regulamentação do bem-estar social e priorizam a administração penal dos rejeitados humanos da sociedade do mercado". Nesse sentido, colocados à margem para serem capturados por quem os abandona, usuários e traficantes tornam-se um conjunto de corpos úteis e produtivos ao sistema capitalista por meio, por exemplo, da exploração de sua mão de obra, travestida pela ideia de uma atividade de trabalho, com fins de ressocialização nas prisões e comunidades terapêuticas, mas, principalmente, funcionando como objetos da sociedade do mercado, corpos dóceis e úteis para a criação de postos de trabalho diretos ou indiretos, no campo da segurança pública, da saúde e da assistência social.

Paradoxalmente, se usuários de drogas, sobretudo aqueles considerados abusivos ou dependentes, e os trabalhadores do tráfico de drogas não estão, inicialmente, circunscritos à lógica do mercado formal de trabalho, é justamente pelo viés do encarceramento, seja o encarceramento punitivo, seja o terapêutico, que esses sujeitos "recuperam" sua utilidade ao sistema neoliberal.

\section{CONSIDERAÇÕES FINAIS}

Pode-se concluir que o que se institui em torno da droga ilícita, enquanto mercadoria, é um campo de disputa política, no qual a vida, apreendida como precária, não é reconhecida, restringindo-se a um corpo sem logos. É sempre um outro que fala em seu nome, por meio do discurso moral, religioso, científico ou jurídico. Entretanto, as medidas violentas relativas à restrição da produção, venda ou uso de drogas, provam a insuficiência dos saberes que pretendem dominá-las.

A proibição arbitrária de algumas drogas, em detrimento de outras, permite ao Estado expor a vida à insegurança, delimitar as fronteiras normativas da subjetividade e, assim, regulá-la e controlá-la melhor. Nessa perspectiva, as relaçóes de saber e poder que a droga contempla, enquanto um dispositivo, permitem administrar a vida dos homens, pois ela contém em si uma promessa de prazer e felicidade e, ao mesmo tempo, uma ameaça de sofrimento e morte. 
Trata-se, como bem apontou Silva (2011), de uma interdição sem sentido, que irá acarretar uma punição injusta e produzir um sistema terapêutico que não sabe o que curar. A severidade policial associa-se à benevolência terapêutica que tem por função julgar quem é ou não elegível para usar e/ou comercializar drogas, por meio de uma suposta avaliação se o sofrimento diante de um malestar é normal e, portanto, deve ser tolerado, ou se é patológico e deve ser tratado.

Compreende-se assim que as formas de governo que incidem sobre essa população marginal têm se dado de maneira a legitimar processos de abjeção social. Essa estratégia atende perfeitamente aos interesses econômicos de determinados grupos sociais que lucram com o encarceramento da população marginalizada e com a medicalização da vida.

Desmascarar os subterfúgios produzidos nas tramas neoliberais faz parte de um compromisso ético-político para a construção de um futuro outro, livre, ou ao menos, crítico aos determinismos que legitimam a segregação, a exclusão, a matança daqueles que, contingencialmente, têm inscrita nos seus corpos a condição de abjetos. No que tange ao campo da droga, é urgente pôr fim à falaciosa e danosa política de guerra. Se, no terreno da saúde pública, os avanços teórico-práticos, como demonstra Silva (2012), tecidos na Reforma Psiquiátrica, já apontam saídas, ainda que pouco investidas, não segregatórias, pautadas por um cuidado de si, entrelaçado com a cidade, na esfera da segurança pública, parcos são os progressos. São imperiosos avanços legislativos, de forma a legalizar e, portanto, regulamentar a produção, a comercialização e o consumo de todas as drogas. É imperativo resistir, nas dobras do sistema, ao triunfo do mercado, ao esmagamento da vida humana pelo capital. 


\section{REFERÊNCIAS}

Agambem, G. (2010). Homo Sacer: o poder do soberano e a vida nua. (2a ed.). Belo Horizonte: UFMG.

Alkmim, W. D. (2008). Construir o caso clínico: a instituição enquanto exceção. Clini CAPS [online], 2(4),10-10.

Almeida, D. T. (2012). Análise do trabalho de uma equipe multiprofissional em um Centro de Atenção Psicossocial álcool e drogas. (Dissertação de Mestrado). Universidade Federal de Minas Gerais, Belo Horizonte.

Amaral, T. V. F. (2014). Vamos à atividade do dia: o acerto de contas no trabalho do tráfico de drogas varejista. (Dissertação de Mestrado). Universidade Federal de Minas Gerais, Faculdade de Filosofia e Ciências Humanas, Belo Horizonte.

Butler, Judith (2002a). Como os corpos se tornam matéria: entrevista com Judith Butler.Entrevista concedida a Baukje Prins e Irene Costera Meijer. Revista Estudos Feministas [online], 10(1), p. 155-167.

Butler, J. (2002b). Cuerpos que importan: sobre los limites materiales y discursivos del "sexo". Buenos Aires: Paidós.

Butler, J. (2006). Deshacer el género. Buenos Aires: Paidós.

Butler, J. (2011). Vida Precária. Contemporânea: revista de Sociologia da UFSCar, 1(1), p. 13-33.

Butler, J. (2015). Quadros de guerra: quando a vida é passivel de luto? Rio de Janeiro: Civilização Brasileira.

Duarte, A. (2013). Foucault e governamentalidade: genalogia do liberalismo e do Estado Moderno. In G. Castelo-Branco \& A. Veiga-Neto, (Orgs.). Foucault: filosofia e política. Belo Horizonte: Autêntica.

Escohotado, A. (1998). Historia general de las drogas. Madri: Espasa Calpe.

Foucault, M. (1999). Em defesa da sociedade. São Paulo: Martins Fontes.

Karam, M. L. (2012). Por que o modelo proibicionista ainda avança? In: C. Magalhães, V. Mattos \& J. L. Q. Magalhães. (Orgs.). Desconstruindo práticas punitivas. Belo Horizonte: Grupo de Amigos e Familiares de Pessoas em Privação de Liberdade/Cress 6a região. 
Lukács, G. (2003). História e consciência de classe: estudos sobre a dialética marxista. São Paulo: Martins Fontes. [Trabalho original publicado em 1923].

Marx, K. Mercadoria e dinheiro (2013). In K. Marx. O capital: crítica da economia política. Livro I: o processo de produção do capital. (31a ed.). R. Sant'Anna (Trad.). Rio de Janeiro: Civilização Brasileira.

Melo, R. A. C. (2010). Onde o mal está na civilização? Clini CAPS, 4(10), p. $1-9$.

Santiago, J. (2001). A droga do toxicômano: uma parceria cinica na era da ciência. Rio de Janeiro: Jorge Zahar Editor.

Silva, E. R. (2010). A atividade de trabalho do psiquiatra no CAPS - Centro de Atenção Psicossocial: pois é José... (Dissertação de mestrado). Universidade Federal de Minas Gerais. Belo Horizonte, MG, Brasil.

Silva, L. F. C. (2011). Cidade limpa, cidade suja: biopolítica e fascismo nas culturas urbanas contemporâneas. Recuperado a partir de http://www.leapbrasil.com. br/site/wp-content/uploads/2017/03/35_CIDADE-LIMPA-3__revisado_.pdf

Silva, R. A. (2012, Setembro/fevereiro). No meio de todo caminho, sempre haverá uma pedra. Revista Responsabilidades, Belo Horizonte, 1(2), 203-214.

Tiburi, M. \& Dias, A. C. (2013). Sociedade fissurada. Rio de Janeiro: Civilização Brasileira.

Vargas, E. V. (2001). Entre a extensão e a intensidade: corporalidade, subjetivação e uso de drogas. (Tese de Doutorado). Universidade Federal de Minas Gerais, Faculdade de Filosofia e Ciências Humanas, Belo Horizonte.

Vargas, E. V. (2006). Uso de drogas: a alter-ação como evento. Revista de Antropologia USP São Paulo, 49(2), 581-623.

Vianna, P. C. (2009). A produção do "problema da droga" como caso de polícia e saúde pública. (Dissertação de mestrado). Universidade Federal Fluminense, Instituto de Ciências Humanas e Filosofia, Niterói, RJ.

Wacquant, L. (2008). As duas faces do gueto. São Paulo: Boitempo. 